\title{
Particulate Matter of Different Sizes Associated With Acute Lower Respiratory Infection Outpatient Visits in Children: A Time-Series Analysis in Guangzhou, China
}

\section{Zhenyu Liang}

Guangdong Second Provincial General Hospital

\section{Qiong Meng}

Guangdong Second Provincial General Hospital

Qiaohuan Yang

Guangdong Second Provincial General Hospital

$\mathrm{Na}$ Chen

Guangdong Second Provincial General Hospital

Chuming You ( $\nabla$ gd2hek@163.com )

Guangdong Second Provincial General Hospital https://orcid.org/0000-0001-6262-3463

\section{Research}

Keywords: particulate matter, particle, lower respiratory infection, China

Posted Date: May 6th, 2021

DOI: https://doi.org/10.21203/rs.3.rs-474721/v1

License: (c) (1) This work is licensed under a Creative Commons Attribution 4.0 International License.

Read Full License 


\section{Abstract \\ Background}

The burden of lower respiratory infection is primarily borne by developing countries. However, the association between particulate matter of different sizes and acute lower respiratory infection (ALRI) outpatient visits in developing countries is less studied.

\section{Methods}

We obtained data on ALRI outpatient visits $(\mathrm{N}=105,639)$ from a tertiary hospital in Guangzhou, China between 2013 and 2019. Over-dispersed generalized additive Poisson models were employed to evaluate the excess risk (ER) associated with particulate matter [inhalable particulate matter $\left(\mathrm{PM}_{10}\right)$, coarse particulate matter $\left(P M_{c}\right)$, and fine particulate matter $\left(P M_{2.5}\right)$ ]. Counterfactual analyses were used to examine the potential percent reduction of ALRI outpatient visits if the levels of air pollution were as low as those recommended by the World Health Organization (WHO).

\section{Results}

There were 35,310 pneumonia, 68,218 bronchiolitis, and 2,111 asthma outpatient visits included. Each 10 $\mu \mathrm{g} / \mathrm{m}^{3}$ increase of three-day moving averages of particulate matter was associated with significant ER [95\% confidence interval $(\mathrm{Cl})]$ of outpatient visits of pneumonia $\left[\mathrm{PM}_{2.5}: 3.71 \%(2.91 \%, 4.52 \%) ; \mathrm{PM}_{\mathrm{c}}: 9.19 \%\right.$ (6.94\%, 11.49\%); $\mathrm{PM}_{10}: 4.36 \%$ (3.21\%, 5.52\%)], bronchiolitis $\left[\mathrm{PM}_{2.5}: 3.21 \%(2.49 \%, 3.93 \%) ; \mathrm{PM}_{\mathrm{c}}: 9.13 \%\right.$ (7.09\%, 11.21\%); $\left.\mathrm{PM}_{10}: 3.12 \%(2.10 \%, 4.15 \%)\right]$, and asthma $\left[\mathrm{PM}_{2.5}: 3.45 \%\right.$ (1.18\%, 5.78\%); $\mathrm{PM}_{\mathrm{c}}: 11.69 \%$ $\left.(4.45 \%, 19.43 \%) ; \mathrm{PM}_{10}: 3.33 \%(0.26 \%, 6.49 \%)\right]$. The association between particulate matter and pneumonia outpatient visits was stronger among male patients and in cold seasons. Counterfactual analyses suggested that $\mathrm{PM}_{2.5}$ was associated with the largest potential decline of ALRI outpatient visits [pneumonia: $3.89 \%, 95 \%$ Cl: (3.24\%, 5.52\%); bronchiolitis: 4.35\% (3.06\%, 4.82\%); asthma: $5.98 \%$ (1.92\%, $10.37 \%)$ if the air pollutants were reduced to the level of the reference guidelines.

\section{Conclusion}

Short-term exposure to $\mathrm{PM}_{2.5}, \mathrm{PM}_{\mathrm{C}}$, and $\mathrm{PM}_{10}$ is associated with significant risk of ALRI outpatient visits, among which $\mathrm{PM}_{2.5}$ is associated with the highest potential decline in outpatient visits if it could be reduced to the WHO recommended level.

\section{Introduction}


Lower respiratory infections, also known as pneumonia or bronchiolitis, are the sixth leading cause of death for all ages, resulting in around 2.4 million deaths worldwide in 2016[1]. The burden of lower respiratory infections is unevenly distributed across the globe and primarily born in developing countries and socioeconomically disadvantaged communities, where adequate nutrition, clean fuel, sanitation, and clean air are unavailable[2, 3].

Exposure to ambient particulate matter (PM) has been widely reported to be associated with lower respiratory infection[4-6]. However, evidence on the association between different sizes of PM and lower respiratory infections, especially that from developing countries in which the level of air pollution is high, is relatively little[7-9]. Meanwhile, it is widely acknowledged that short-term exposure to particulate matter is associated with ALRI hospitalizations[10-14], but we have not found any study that investigated the association between exposure to particulate matter and ALRI outpatient visits.

In this time-series analyses of outpatient visits in a tertiary hospital in Guangzhou, China from 2013 to 2019, we investigate the association between $P M$ of different sizes $\left(\mathrm{PM}_{10}, \mathrm{PM}_{\mathrm{C}}\right.$, and $\left.\mathrm{PM}_{2.5}\right)$ and the outpatient visits of ALRI, potential mediators, and the potential percent reduction of ALRI outpatient visits if the levels of particulate matter were as low as those recommended by the WHO.

\section{Methods}

\section{Acute lower respiratory infection data}

Data on hospital outpatient visits for ALRI were retrieved from the Guangdong Second Provincial General Hospital located in the southwest of the city (Figure 1), which is one of the highest-level (tertiary) hospitals in Guangzhou[15]. According to the International Classification of Diseases, Tenth Revision (ICD-10), hospital outpatient visits with the primary diagnoses of pneumonia (J12-J18), bronchiolitis (J20-J21), and asthma (J45-J46)[16] were obtained between February 2013 and December 2019. We aggregated the three subtypes of ALRI to a series of daily time-series data[17-20].

\section{Air pollution and meteorological data}

Daily concentrations of air pollution during the study period were obtained from 11 air monitoring stations in Guangzhou (Figure 1), including inhalable particulate matter $\left(\mathrm{PM}_{10}\right)$, coarse particulate $\left(\mathrm{PM}_{\mathrm{c}}\right)$, fine particulate matter $\left(\mathrm{PM}_{2.5}\right)$, nitrogen dioxide $\left(\mathrm{NO}_{2}\right)$, sulfur dioxide $\left(\mathrm{SO}_{2}\right)$ and ozone $\left(\mathrm{O}_{3}\right)$. Following previous study[19], the $\mathrm{PM}_{\mathrm{c}}$ concentrations were calculated by subtracting $\mathrm{PM}_{2.5}$ from $\mathrm{PM}_{10}$, because $\mathrm{PM}_{10}$ was consisted of $\mathrm{PM}_{2.5}$ and $\mathrm{PM}_{\mathrm{c}}$. Air pollution measurement details have been previously described[21]. Approximately $1 \%$ of observation days had missing data for the air pollution, the missing data were imputed using a linear interpolation approach (the "na.approx" function in "zoo" package in R).

Daily meteorological data (mean temperature and relative humidity) were obtained from the National Weather Data Sharing System (http://data.cma.cn/). Because there is potentially high correlation among 
different air pollutants and meteorological factors, we examined the pairwise Pearson correlation coefficients among these variables.[22, 23]

\section{Statistical models}

The ALRI data, daily air pollution concentrations and meteorological data were linked by date. Following prior similar epidemiology studies[24], the association between PM pollution and hospital outpatient visits for acute lower respiratory infections diseases was examined by an over-dispersed generalized additive Poisson model (GAM). In the model, public holidays (PH) and day of the week (DOW) were adjusted for as categorical variables. Seasonal patterns, long-term trends, temperature, and relative humidity were controlled for as smoothing splines. In accordance with the approaches used in previous studies[25, 26], we selected six degrees of freedom (df) per year for temporal trends, a df of 6 for moving average temperature of the current day and previous three days (Temp03) and relative humidity (RH).

Considering the delayed health effects of air pollutants, we examined the lag effects for different lag structures. We begin with the same day (lag0) up to five days lag (lag5) in the single-lag day models. We also considered the accumulated effects of multi-day lags (moving averages for the current day and the previous 1, 2 and 3 days [lag01, lag02, and lag03]).

\section{Stratified analyses}

In order to evaluate the potential effect modifiers of the PM pollution-ALRI associations, we conducted stratified analyses by gender (male vs. female), age group (age $<5$ vs. age $5-14$ ), and season (warm vs. cold). The warm season was defined as from April to September, and the cold season was from October to March. The $95 \%$ confidence interval $(\mathrm{Cl})$ of the difference between group was calculated by the formula below:

$$
Q_{1}-Q_{2} \pm 1.96 \sqrt{\left(\mathrm{SE}_{1}\right)^{2}+\left(\mathrm{SE}_{2}\right)^{2}}
$$

where Q represents the estimated coefficient in each stratum, and SE is the corresponding standard error[27]. The difference was considered as statistically significant if the $95 \% \mathrm{Cl}$ did not include unity.

\section{Sensitivity analyses}

To examine the robustness of the main models, we applied a series of sensitivity studies. The main findings were assessed by changing the $\mathrm{df}$ in the smooth functions for temporal trends and meteorological factors. Additionally, we adjusted for gaseous air pollutants $\left(\mathrm{SO}_{2}, \mathrm{NO}_{2}\right.$, and $\left.\mathrm{O}_{3}\right)$ in twopollutant models. The models were regarded as robust if there were no significant changes after dfchanged or further adjustment for gaseous air pollutants.

\section{Counterfactual analyses on the burden of ALRI attributable to air pollution}


We estimated the burden of ALRI attributable to $\mathrm{PM}_{2.5}, \mathrm{PM}_{\mathrm{C}}$, and $\mathrm{PM}_{10}$ by calculating the difference between the observed ALRI outpatient visits and the counterfactual visits predicted using well-recognized reference values of air pollution recommended by the World Health Organization (WHO) and our previously built over-dispersed generalized additive Poisson models. This difference between the observed and counterfactual ALRI outpatient visits represents the estimated burden of ALRI outpatient visits associated with particulate matter of different sizes. The counterfactual scenarios were set to be hypothetical values of $\mathrm{PM}_{2.5}, \mathrm{PM}_{\mathrm{C}}$ and $\mathrm{PM}_{10}$ set by the WHO Air Quality Guidelines (24 hours mean: 25 $\mu \mathrm{g} / \mathrm{m}^{3}$ for $\mathrm{PM}_{2.5}, 25 \mu \mathrm{g} / \mathrm{m}^{3}$ for $\mathrm{PM}_{\mathrm{c}}$, and $50 \mu \mathrm{g} / \mathrm{m}^{3}$ for $\mathrm{PM}_{10}$ ). The observed air pollution levels lower than the reference values were kept the same in the counterfactual scenario. The $95 \% \mathrm{Cls}$ were constructed using 1,000 bootstrap replicates with replacement for each model.[28, 29]

In all statistical analyses, a $\mathrm{P}$ value $\leq 0.05$ was considered statistically significant. All data cleaning, aggregation, and visualization, and statistical analyses were done using statistical computing environment $\mathrm{R}$ (version 4.0.5)[30].

\section{Results}

Figure 1 presents the geographical location of Guangzhou city and the sample hospital, as well as the geographical distribution of the air monitoring stations in Guangzhou. A total of 35,310 pneumonia, 68,218 bronchiolitis, and 2,111 asthma cases were included in our analyses. Table 1 shows the summary statistics of ALRI subtypes, particulate matter of different sizes $\left(\mathrm{PM}_{10}, \mathrm{PM}_{\mathrm{C}}\right.$, and $\left.\mathrm{PM}_{2.5}\right)$, and gaseous pollutants $\left(\mathrm{SO}_{2}, \mathrm{NO}_{2}\right.$, and $\left.\mathrm{O}_{3}\right)$. The daily averages [standard deviations (SD)] of pneumonia, bronchiolitis, and asthma cases were 12.5 (9.1), 24.3 (11.5), and 0.8 (1.4). The mean concentrations of $\mathrm{PM}_{10}, \mathrm{PM}_{\mathrm{C}^{\prime}}$ and $\mathrm{PM}_{2.5}$ in our study were $58.3,21.0$, and $37.8 \mu \mathrm{g} / \mathrm{m}^{3}$. The mean (SD) of temperature and relative humidity was $22.8(5.9){ }^{\circ} \mathrm{C}$ and $81.8 \%(10.2 \%)$. 
Table 1

Summary statistics of acute lower respiratory infections outpatient visits, air pollutants, and meteorological variables.

\begin{tabular}{|c|c|c|c|c|c|c|c|}
\hline & \multirow[t]{2}{*}{ Mean } & \multirow[t]{2}{*}{ SD } & \multicolumn{5}{|c|}{ Percentile } \\
\hline & & & Min & 25th & 50th & 75th & Max \\
\hline \multicolumn{8}{|c|}{ Acute lower respiratory infections } \\
\hline Pneumonia & 12.5 & 9.1 & 0.0 & 6.0 & 11.0 & 16.0 & 73.0 \\
\hline Bronchiolitis & 24.3 & 11.5 & 0.0 & 16.0 & 23.0 & 31.0 & 81.0 \\
\hline Asthma & 0.8 & 1.4 & 0.0 & 0.0 & 0.0 & 1.0 & 12.0 \\
\hline \multicolumn{8}{|l|}{ Air pollution, $\mu \mathrm{g} / \mathrm{m}^{3}$} \\
\hline $\mathrm{PM}_{10}$ & 58.3 & 28.1 & 10.0 & 38.2 & 51.1 & 73.4 & 217.8 \\
\hline $\mathrm{PM}_{\mathrm{c}}$ & 21.0 & 9.9 & 0.8 & 14.7 & 18.8 & 25.3 & 77.7 \\
\hline $\mathrm{PM}_{2.5}$ & 37.8 & 21.2 & 4.6 & 22.7 & 32.3 & 48.3 & 156.4 \\
\hline $\mathrm{SO}_{2}$ & 13.6 & 8.5 & 2.8 & 8.6 & 11.9 & 16.5 & 166.4 \\
\hline $\mathrm{NO}_{2}$ & 45.2 & 18.6 & 4.4 & 33.6 & 41.2 & 53.7 & 177.7 \\
\hline $\mathrm{O}_{3}$ & 51.6 & 30.2 & 3.5 & 30.0 & 47.2 & 67.1 & 294.6 \\
\hline \multicolumn{8}{|c|}{ Meteorological variables } \\
\hline Temperature, ${ }^{\circ} \mathrm{C}$ & 22.8 & 5.9 & 1.7 & 19.0 & 25.0 & 27.5 & 32.8 \\
\hline Relative humidity, \% & 81.8 & 10.2 & 30.5 & 77.0 & 83.1 & 89.3 & 100.0 \\
\hline
\end{tabular}

Figure 2 shows the correlation plot of the air pollutants and meteorological variables in our sample. All the Pearson correlation coefficients were statistically significant except for the correlation between $\mathrm{NO}_{2}$ and $\mathrm{O}_{3}$. $\mathrm{PM}_{10}$ was significantly and strongly correlated with $\mathrm{PM}_{\mathrm{c}}$ and $\mathrm{PM}_{2.5}$ (Pearson correlation coefficients: 0.81 and 0.93 ); $\mathrm{NO}_{2}$ was moderately correlated with particulate matters (Pearson correlation coefficients for $\mathrm{PM}_{10}, \mathrm{PM}_{\mathrm{C}}$, and $\mathrm{PM}_{2.5}: 0.78,0.66$, and 0.70 ). Meteorological variables were negatively correlated with air pollutants except for the positive correlation between temperature and $\mathrm{O}_{3}$.

Table 2 exhibits the ER of pneumonia, bronchiolitis, and asthma outpatient visits associated with per 10 $\mu \mathrm{g} / \mathrm{m}^{3}$ increase of $\mathrm{PM}_{2.5}, \mathrm{PM}_{\mathrm{c}}$, and $\mathrm{PM}_{10}$ in lag03. The results revealed that particulate matters of different sizes were significantly associated with pneumonia, bronchiolitis, and asthma, respectively in single-pollutant models, where the ER of $\mathrm{PM}_{\mathrm{C}}$ is the largest, followed by those of $\mathrm{PM}_{2.5}$ and $\mathrm{PM}_{10}$. The 
results were consistent and robust in two-pollutant models with further adjustment for $\mathrm{SO}_{2}, \mathrm{NO}_{2}$, and $\mathrm{O}_{3}$, except for those asthma models controlling for $\mathrm{NO}_{2}$. The corresponding exposure-response nonlinear curves for daily particulate matter and log relative risk are provided in Supplemental Fig. 1.

Table 2

Excess risk and $95 \%$ confidence intervals of pneumonia, bronchiolitis, and asthma for each $10 \mu \mathrm{g} / \mathrm{m}^{3}$ increase in $\mathrm{PM}_{2.5}, \mathrm{PM}_{\mathrm{C}}, \mathrm{PM}_{10}$ using single- and two-pollutants models.

\begin{tabular}{|c|c|c|c|c|}
\hline Pollutants & Models & Pneumonia & Bronchiolitis & Asthma \\
\hline \multicolumn{5}{|l|}{$\mathrm{PM}_{10}$} \\
\hline & Single-pollutant model & $3.71(2.91,4.52)$ & $3.21(2.49,3.93)$ & $3.45(1.18,5.78)$ \\
\hline & \multicolumn{4}{|l|}{ Two-pollutant models } \\
\hline & Control for $\mathrm{SO}_{2}$ & $3.81(2.97,4.66)$ & $3.44(2.69,4.21)$ & $3.46(1.13,5.85)$ \\
\hline & Control for $\mathrm{NO}_{2}$ & $2.47(1.47,3.47)$ & $1.48(0.58,2.37)$ & $0.26(-2.58,3.19)$ \\
\hline & Control for $\mathrm{O}_{3}$ & $4.06(3.22,4.91)$ & $3.48(2.72,4.25)$ & $3.72(1.30,6.20)$ \\
\hline \multicolumn{5}{|l|}{$\mathrm{PM}_{\mathrm{c}}$} \\
\hline & Single-pollutant model & $9.19(6.94,11.49)$ & $9.13(7.09,11.21)$ & $11.69(4.45,19.43)$ \\
\hline & \multicolumn{4}{|l|}{ Two-pollutant models } \\
\hline & Control for $\mathrm{SO}_{2}$ & $9.32(6.98,11.72)$ & $9.72(7.58,11.91)$ & $11.70(4.29,19.63)$ \\
\hline & Control for $\mathrm{NO}_{2}$ & $5.58(3.03,8.19)$ & $4.80(2.45,7.20)$ & $3.26(-4.88,12.09)$ \\
\hline & Control for $\mathrm{O}_{3}$ & $9.52(7.21,11.87)$ & $9.47(7.37,11.61)$ & $12.09(4.56,20.17)$ \\
\hline \multicolumn{5}{|l|}{$\mathrm{PM}_{2.5}$} \\
\hline & Single-pollutant model & $4.36(3.21,5.52)$ & $3.12(2.10,4.15)$ & $3.33(0.26,6.49)$ \\
\hline & \multicolumn{4}{|l|}{ Two-pollutant models } \\
\hline & Control for $\mathrm{SO}_{2}$ & $4.61(3.37,5.87)$ & $3.50(2.39,4.63)$ & $3.45(0.14,6.87)$ \\
\hline & Control for $\mathrm{NO}_{2}$ & $2.30(0.96,3.65)$ & $0.39(-0.78,1.58)$ & $-0.40(-3.86,3.18)$ \\
\hline & Control for $\mathrm{O}_{3}$ & $4.85(3.63,6.09)$ & $3.38(2.29,4.48)$ & $3.54(0.26,6.91)$ \\
\hline
\end{tabular}

Similar patterns of ER of ALRI outpatient visits associated with per $10 \mu \mathrm{g} / \mathrm{m}^{3}$ increase in different size fractions could be observed in Fig. 3. Each $10 \mu \mathrm{g} / \mathrm{m}^{3}$ increase in $P M_{2.5}, P M_{c}, P M_{10}$ was associated with outpatient visits of pneumonia, bronchiolitis, and asthma in different lag days. In contrast, the effects of matter of different sizes on asthma are less robust: the moving average lags of $\mathrm{PM}_{\mathrm{C}}$, and $\mathrm{PM}_{2.5}$ were still 
significantly associated with ALRI outpatient visits, but the effects of lag0 to lag5 of $\mathrm{PM}_{\mathrm{C}}$ and $\mathrm{PM}_{2.5}$ and different lags of $\mathrm{PM}_{10}$ were nonsignificant or at borderline significant.

Table 3 presents the estimated ER with $95 \% \mathrm{Cl}$ of pneumonia, bronchiolitis, and asthma stratified by gender, age group, and season, where the bold numbers indicate significant differences across strata. We can observe that each $10 \mu \mathrm{g} / \mathrm{m}^{3}$ increases in $\mathrm{PM}_{10}, \mathrm{PM}_{\mathrm{C}}$, and $\mathrm{PM}_{2.5}$ were consistently associated with significantly different effects on pneumonia outpatient visits by gender and season groups. Similar differential effects can be observed for bronchiolitis associated with increases in $\mathrm{PM}_{10}$ and $\mathrm{PM}_{\mathrm{C}}$ by different season strata, but not for $\mathrm{PM}_{2.5}$. However, the differential effects across strata were much less significant for asthma outpatient visits: it was only significantly different between warm and cold seasons. 
Table 3

Excess risk and $95 \%$ confidence intervals of pneumonia, bronchiolitis, and asthma for each $10 \mu \mathrm{g} / \mathrm{m}^{3}$ increase in $\mathrm{PM}_{2.5}, \mathrm{PM}_{\mathrm{c}}$, and $\mathrm{PM}_{10}$ stratified by gender, age group, and season.

\begin{tabular}{|c|c|c|c|c|}
\hline Pollutants & Stratum & Pneumonia & Bronchiolitis & Asthma \\
\hline \multicolumn{5}{|l|}{$\mathrm{PM}_{10}$} \\
\hline & \multicolumn{4}{|l|}{ Gender } \\
\hline & Male & $4.49(3.54,5.45)$ & $3.44(2.68,4.21)$ & $4.46(1.62,7.39)$ \\
\hline & Female & $2.68(1.61,3.75)$ & $2.76(1.84,3.69)$ & $1.78(-1.51,5.18)$ \\
\hline & \multicolumn{4}{|l|}{ Age } \\
\hline & $<5$ & $3.50(2.66,4.34)$ & $3.09(2.36,3.82)$ & $1.78(-0.97,4.60)$ \\
\hline & $5-14$ & $4.50(2.71,6.33)$ & $3.70(2.49,4.92)$ & $6.01(2.39,9.75)$ \\
\hline & \multicolumn{4}{|l|}{ Season } \\
\hline & Warm & $-0.06(-1.24,1.13)$ & $2.13(1.03,3.23)$ & $6.53(2.52,10.69)$ \\
\hline & Cold & $5.12(4.00,6.25)$ & $3.76(2.74,4.79)$ & $1.76(-1.00,4.61)$ \\
\hline \multicolumn{5}{|l|}{$\mathrm{PM}_{\mathrm{c}}$} \\
\hline & \multicolumn{4}{|l|}{ Gender } \\
\hline & Male & $11.07(8.36,13.83)$ & $10.02(7.82,12.25)$ & $15.65(6.36,25.74)$ \\
\hline & Female & $6.70(3.78,9.71)$ & $7.57(4.99,10.21)$ & $5.94(-3.96,16.87)$ \\
\hline & \multicolumn{4}{|l|}{ Age } \\
\hline & $<5$ & $8.69(6.37,11.06)$ & $8.76(6.69,10.88)$ & $6.96(-1.69,16.38)$ \\
\hline & $5-14$ & $10.76(5.65,16.13)$ & $10.75(7.34,14.27)$ & $17.98(6.46,30.74)$ \\
\hline & \multicolumn{4}{|l|}{ Season } \\
\hline & Warm & $-0.93(-4.33,2.60)$ & $3.77(0.40,7.26)$ & $22.14(6.92,39.53)$ \\
\hline & Cold & $13.57(10.46,16.77)$ & $11.92(9.07,14.84)$ & $9.39(0.93,18.56)$ \\
\hline \multicolumn{5}{|l|}{$\mathrm{PM}_{2.5}$} \\
\hline & \multicolumn{4}{|l|}{ Gender } \\
\hline & Male & $5.31(3.95,6.69)$ & $3.48(2.39,4.58)$ & $4.13(0.30,8.09)$ \\
\hline
\end{tabular}

The bold type represents the statistically significant differences $(p<0.05)$.

Warm season: April to September; cold season: October to March. 


\begin{tabular}{|cllll|}
\hline Pollutants & Stratum & Pneumonia & Bronchiolitis & Asthma \\
\hline Female & $\mathbf{3 . 1 1}(\mathbf{1 . 5 8 , 4 . 6 5 )}$ & $2.45(1.14,3.78)$ & $1.92(-2.54,6.58)$ \\
\hline Age & & & \\
\hline$<$ & $4.07(2.87,5.28)$ & $2.88(1.84,3.93)$ & $1.53(-2.16,5.35)$ \\
\hline $5-14$ & $5.59(3.07,8.17)$ & $4.10(2.39,5.85)$ & $6.13(1.22,11.28)$ \\
\hline Season & & & \\
\hline Warm & $\mathbf{0 . 0 8}(-1.49,1.67)$ & $3.00(1.56,4.46)$ & $\mathbf{7 . 7 3}(2.62,13.08)$ \\
\hline Cold & $\mathbf{6 . 0 8 ( 4 . 4 2 , 7 . 7 7 )}$ & $3.01(1.51,4.53)$ & $-\mathbf{0 . 3 0}(-4.05,3.60)$ \\
\hline \multicolumn{4}{|l}{ The bold type represents the statistically significant differences $(p<0.05)}$. \\
\hline
\end{tabular}

Table 4 shows the proportion reduction of ALRI (pneumonia, bronchiolitis, and asthma) outpatient visits attributable to $\mathrm{PM}_{2.5}, \mathrm{PM}_{\mathrm{C}}$, and $\mathrm{PM}_{10}$ in Guangzhou from 2013 to 2019 using counterfactual analysis that compares to the WHO recommended levels $\left(25 \mu \mathrm{g} / \mathrm{m}^{3}\right.$ for $\mathrm{PM}_{2.5}, 25 \mu \mathrm{g} / \mathrm{m}^{3}$ for $\mathrm{PM}_{\mathrm{C}}$, and $50 \mu \mathrm{g} / \mathrm{m}^{3}$ for $\mathrm{PM}_{10}$ ). We found that $\mathrm{PM}_{2.5}$ was associated with the largest decline of ALRI outpatient visits [pneumonia: 3.89\%, 95\% Cl: (3.24\%, 5.52\%); bronchiolitis: $4.35 \%, 95 \%$ Cl: (3.06\%, 4.82\%); asthma: $5.98 \%, 95 \% \mathrm{Cl}$ :

$(1.92 \%, 10.37 \%)]$ if the levels of air pollution were reduced to the level of the reference guidelines specified by the WHO.

Table 4

Counterfactual analysis on the percent of decline ( $95 \%$ confidence intervals) in acute lower respiratory infection outpatient visits if the level of $\mathrm{PM}_{2.5}, \mathrm{PM}_{\mathrm{c}}$, and $\mathrm{PM}_{10}$ were reduced to the reference levels in Guangzhou from 2013 to 2019.

\begin{tabular}{|lccc|}
\hline & Pneumonia & Bronchiolitis & Asthma \\
\hline $\mathrm{PM}_{10}$ & $3.89 \%(3.24 \%, 5.52 \%)$ & $4.35 \%(3.06 \%, 4.82 \%)$ & $5.98 \%(1.92 \%, 10.37 \%)$ \\
\hline $\mathrm{PM}_{\mathrm{C}}$ & $1.42 \%(1.10 \%, 1.82 \%)$ & $1.91 \%(1.48 \%, 2.36 \%)$ & $1.79 \%(0.60 \%, 3.09 \%)$ \\
\hline $\mathrm{PM}_{2.5}$ & $4.63 \%(3.47 \%, 5.98 \%)$ & $4.38 \%(2.68 \%, 5.97 \%)$ & $6.07 \%(0.08 \%, 12.37 \%)$ \\
\hline $\begin{array}{l}\text { The references of } \mathrm{PM}_{10}, \mathrm{PM}_{2.5} \text {, and } \mathrm{PM}_{\mathrm{c}} \text { concentration were based on the World Health Organization's } \\
\text { Ambient Air Quality guidelines }\left(24 \mathrm{~h} \text { mean: } 50 \mu \mathrm{g} / \mathrm{m}^{3} \text { for } \mathrm{PM}_{10}, 25 \mu \mathrm{g} / \mathrm{m}^{3} \text { for } \mathrm{PM}_{\mathrm{C}} \text {, and } 25 \mu \mathrm{g} / \mathrm{m}^{3} \text { for }\right. \\
\mathrm{PM}_{2.5} \text {, respectively). }\end{array}$ & \\
\hline
\end{tabular}

\section{Discussion}

In this seven-year time-series analyses of daily ALRI outpatient visits data $(N=105,639)$ in Guangzhou, China from 2013 to 2019, we observed statistically significant ERs and potential declination of ALRI 
(including pneumonia, bronchiolitis, and asthma) outpatient visits associated with particulate matter of different sizes. The results were consistent in exposure assessment using different lags (lag 0 to 5 and moving averages of 1 to 3 days), two-pollutant models adjusting for $\mathrm{SO}_{2}, \mathrm{NO}_{2}$, and $\mathrm{O}_{3}$, and various degrees of freedom. In counterfactual analyses that are of more public health significance, $\mathrm{PM}_{2.5}$ was associated with the largest decline of ALRI outpatient visits if the exposure were as low as the WHO guideline reference.

Different effect estimates were observed among different sized PM with the largest ER being observed in $\mathrm{PM}_{\mathrm{C}}$, followed by $\mathrm{PM}_{2.5}$ and $\mathrm{PM}_{10}$. However, these results should be interpreted with caution that $\mathrm{PM}_{2.5}$, $\mathrm{PM}_{\mathrm{C}}$, and $\mathrm{PM}_{10}$ have different means and standard deviations: the mean of $\mathrm{PM}_{\mathrm{C}}$ in our sample (21.0 $\left.\mu \mathrm{g} / \mathrm{m}^{3}\right)$ was lower than the WHO recommended level $\left(25 \mu \mathrm{g} / \mathrm{m}^{3}\right)$; the SD of $\mathrm{PM}_{\mathrm{C}}\left(9.9 \mu \mathrm{g} / \mathrm{m}^{3}\right)$ was much smaller compared to those of $\mathrm{PM}_{2.5}\left(21.2 \mu \mathrm{g} / \mathrm{m}^{3}\right)$ and $\mathrm{PM}_{10}\left(28.1 \mu \mathrm{g} / \mathrm{m}^{3}\right)$. Therefore, the ER of ALRI associated with $\mathrm{PM}_{\mathrm{C}}$ appeared to be the largest, which likely results from its small standard deviation.

In view of the limitation that the calculation of ER largely depends on the statistical distribution of the exposures, we further examined the potential proportion declination that would occur if exposure to particulate matter of different sizes were reduced to the WHO recommended levels $\left(25 \mu \mathrm{g} / \mathrm{m}^{3}\right.$ for $\mathrm{PM}_{2.5}$, $25 \mu \mathrm{g} / \mathrm{m}^{3}$ for $\mathrm{PM}_{\mathrm{c}}$, and $50 \mu \mathrm{g} / \mathrm{m}^{3}$ for $\mathrm{PM}_{10}$ ). In contrast to the result that $\mathrm{PM}_{\mathrm{c}}$ was associated with the highest ER, our counterfactual analysis suggested that reducing $\mathrm{PM}_{2.5}$ to the WHO reference was associated with the largest potential decline in ALRI outpatient visits, followed closely by the reduction of $\mathrm{PM}_{10}$; while reducing $\mathrm{PM}_{\mathrm{C}}$ to the WHO reference is associated with the lowest potential decline in ALRI outpatient visits, which is likely explained by the fact that the mean level of $\mathrm{PM}_{\mathrm{c}}\left(21.0 \mu \mathrm{g} / \mathrm{m}^{3}\right)$ in our sample is lower than that of WHO reference level $\left(25 \mu \mathrm{g} / \mathrm{m}^{3}\right)$.

Our counterfactual analysis results have much more practical public health meaning than those of ER. The implication that reducing the level of $\mathrm{PM}_{2.5}$ may be associated with the largest decline in ALRI outpatient visits is consistent with previous reports about the toxicity of smaller-sized particulate matter on lower respiratory infection hospitalizations[10-14]. For example, Wang et al. specifically focused on the association between particulate matter of different sizes and childhood pneumonia, and they reported a graded impact of particulate matter of different sizes on childhood pneumonia $\left(P_{1}>P_{1} M_{2.5}>P_{10}\right)$. Smaller-sized particulate matter is more likely to enter lower and deeper lobes of lung and cause more severe consequences of health.

Although the air quality has been substantially improved attributable to the effort of air quality management in China over the past decade[31,32], the average level of particulate matter (especially $\mathrm{PM}_{2.5}$ and $\mathrm{PM}_{10}$ ), are still above the WHO recommended level. Northern China cities with high population density can experience anomalously high levels of air pollution during the winter[33]. Our results highlight the importance of focusing on smaller-sized particulate matter due to its harmful effect on ALRI outpatient visits. 
This study should be interpreted in view of several limitations. First, similar to previous time-series studies on air pollution associated health outcomes, we used daily aggregated data to evaluate the short-term effect of particulate matter on health outcomes, but this aggregated nature of data could be subject to ecological bias. Second, we used fixed-site measurement of particulate matter instead of personal exposure, which could lead to inaccurate exposure measurement. Third, we included relatively small number of asthma outpatient visits, which led to unstable point estimates and Cls. Fourth, since we used secondary data collected from the hospital administrative database, environmental and behavior variables that could serve as confounders were not available to us. Lastly, COVID-19 has greatly reshaped the behavior of patient inpatient and outpatient visits, but we were not able to investigate the potential effect of the COVID-19 pandemic on ALRI outpatient visits since the data in this period is not available $[34,35]$.

Nonetheless, this study has several strengths. First, this is the first study that investigates the association between particulate matter of different sizes and subtypes of ALRI outpatient visits, while previous studies either reported the exposure of $\mathrm{PM}_{2.5}$ or hospitalization as the health outcome. Second, we used counterfactual analyses to estimate the potential percent reduction in ALRI outpatient visits compared to the WHO recommended levels. The results of counterfactual analyses have more substantial public health significance compared to ER,OR, and any other estimates associated with fixed amount of increase in particulate matter (such as $10 \mu \mathrm{g} / \mathrm{m}^{3}$ increase in $\mathrm{PM}_{2.5}$ ).

\section{Conclusions}

In summary, this study suggests a larger potential percent of reduction in ALRI outpatient visits if $\mathrm{PM}_{2.5}$ could be as low as the level recommended by the WHO. The association between particulate matter and pneumonia outpatient visits was stronger among male patients and in cold seasons. The results highlight the need for a consolidated effort to reduce the particulate matter pollution of smaller sizes and consequently improve the health outcomes of residents in China.

\section{Abbreviations}

ALRI: Acute lower respiratory infection; Cl: Confidential intervals; RR: Relative risk; ER: Excess risk; WHO: World Health Organization; PM: Particulate matter; $\mathrm{PM}_{10}$ : Particulate matter with an aerodynamic diameter $\leq 10 \mathrm{~mm} ; \mathrm{PM}_{\mathrm{c}}$ : Particulate matter between 2.5 and $10 \mu \mathrm{m}$ in aerodynamic diameter; $\mathrm{PM}_{2.5}$ : Particulate matter with an aerodynamic diameter $\leq 2.5 \mathrm{~mm} \mathrm{SO}_{2}$ : Sulfur dioxide; $\mathrm{NO}_{2}:$ Nitrogen dioxide; $\mathrm{O}_{3}$ : Ozone; GAM: Generalized additive models; DOW: Day of the week; PH: Public holidays; df: Degrees of freedom; ICD-10: International Classification of Diseases, Tenth Revision

\section{Declarations}

\section{Acknowledgements}


The authors thank the Chinese Meteorological Data Sharing Service System for providing the meteorological data used in this study.

Availability of data and materials

Please contact author for data requests.

\section{Funding}

This study was supported by the Science Foundation of Guangdong Second Provincial General Hospital (2021BSGZ001).

\section{Authors' contributions}

Study concept and design were contributed by ZL; statistical analysis was contributed by QM and QY; drafting of the manuscript was contributed by ZL, NC, and CY; All authors contributed to the interpretation of results and manuscript editing; All authors read and approved the final manuscript.

\section{Ethics approval and consent to participate}

Not applicable.

\section{Consent for publication}

Not applicable.

\section{Competing of interests}

The authors declare that they have no competing interests.

\section{References}

1. G. B. D. Causes of Death Collaborators: Global, regional, and national age-sex specific mortality for 264 causes of death, 1980-2016: a systematic analysis for the Global Burden of Disease Study 2016. Lancet 2017, 390(10100):1151-1210.

2. G. B. D. Lower Respiratory Infections Collaborators: Estimates of the global, regional, and national morbidity, mortality, and aetiologies of lower respiratory infections in 195 countries, 1990-2016: a systematic analysis for the Global Burden of Disease Study 2016. Lancet Infect Dis 2018, 18(11):1191-1210.

3. World Health Organization: End preventable deaths: Global action plan for prevention and control of pneumonia and diarrhea. France: UNICEF 2013.

4. Mehta S, Shin H, Burnett R, North T, Cohen AJ: Ambient particulate air pollution and acute lower respiratory infections: a systematic review and implications for estimating the global burden of disease. Air Qual Atmos Health 2013, 6(1):69-83. 
5. Johnston FH, Salimi F, Williamson GJ, Henderson SB, Yao J, Dennekamp M, Smith K, Abramson MJ, Morgan GG: Ambient Particulate Matter and Paramedic Assessments of Acute Diabetic, Cardiovascular, and Respiratory Conditions. Epidemiology 2019, 30(1):11-19.

6. Burnett RT, Pope CA, 3rd, Ezzati M, Olives C, Lim SS, Mehta S, Shin HH, Singh G, Hubbell B, Brauer M et al: An integrated risk function for estimating the global burden of disease attributable to ambient fine particulate matter exposure. Environ Health Perspect 2014, 122(4):397-403.

7. Kurmi OP, Lam KB, Ayres JG: Indoor air pollution and the lung in low- and medium-income countries. Eur Respir J 2012, 40(1):239-254.

8. Horne BD, Joy EA, Hofmann MG, Gesteland PH, Cannon JB, Lefler JS, Blagev DP, Korgenski EK, Torosyan N, Hansen GI et al: Short-Term Elevation of Fine Particulate Matter Air Pollution and Acute Lower Respiratory Infection. Am J Respir Crit Care Med 2018, 198(6):759-766.

9. Gurley ES, Salje H, Homaira N, Ram PK, Haque R, Petri WA, Jr., Bresee J, Moss WJ, Luby SP, Breysse P et al: Indoor exposure to particulate matter and age at first acute lower respiratory infection in a lowincome urban community in Bangladesh. Am J Epidemiol 2014, 179(8):967-973.

10. Wang X, Xu Z, Su H, Ho HC, Song Y, Zheng H, Hossain MZ, Khan MA, Bogale D, Zhang H et al: Ambient particulate matter (PM1, PM2.5, PM10) and childhood pneumonia: The smaller particle, the greater short-term impact? Sci Total Environ 2021, 772:145509.

11. Pu X, Wang L, Chen L, Pan J, Tang L, Wen J, Qiu H: Differential effects of size-specific particulate matter on lower respiratory infections in children: A multi-city time-series analysis in Sichuan, China. Environ Res 2021, 193:110581.

12. Tian Y, Liu H, Wu Y, Si Y, Li M, Wu Y, Wang X, Wang M, Chen L, Wei C et al: Ambient particulate matter pollution and adult hospital admissions for pneumonia in urban China: A national time series analysis for 2014 through 2017. PLoS medicine 2019, 16(12):e1003010.

13. Li D, Wang JB, Zhang ZY, Shen P, Zheng PW, Jin MJ, Lu HC, Lin HB, Chen K: Effects of air pollution on hospital visits for pneumonia in children: a two-year analysis from China. Environ Sci Pollut Res Int 2018, 25(10):10049-10057.

14. Cheng CY, Cheng SY, Chen CC, Pan HY, Wu KH, Cheng FJ: Ambient air pollution is associated with pediatric pneumonia: a time-stratified case-crossover study in an urban area. Environ Health 2019, 18(1):77.

15. Cai M, Liu E, Tao H, Qian Z, Lin X, Cheng Z: Does Level of Hospital Matter? A Study of Mortality of Acute Myocardial Infarction Patients in Shanxi, China. Am J Med Qual 2018, 33(2):185-192.

16. Cai M, Xie Y, Bowe B, Gibson AK, Zayed MA, Li T, Al-Aly Z: Temporal Trends in Incidence Rates of Lower Extremity Amputation and Associated Risk Factors Among Patients Using Veterans Health Administration Services From 2008 to 2018. JAMA Netw Open 2021, 4(1):e2033953.

17. Wang X, Leng M, Liu Y, Qian ZM, Zhang J, Li Z, Sun L, Qin L, Wang C, Howard SW: Different sized particles associated with all-cause and cause-specific emergency ambulance calls: A multicity timeseries analysis in China. Science of The Total Environment 2021, 783:147060. 
18. Wang $X$, Qian Z, Wang $X$, Hong $H$, Yang $Y, X u Y, X u X$, Yao Z, Zhang L, Rolling CA et al: Estimating the acute effects of fine and coarse particle pollution on stroke mortality of in six Chinese subtropical cities. Environmental pollution (Barking, Essex : 1987) 2018, 239:812-817.

19. Wang X, Tian J, Li Z, Lai J, Huang X, He Y, Ye Z, Li G: Relationship between different particle size fractions and all-cause and cause-specific emergency ambulance dispatches. Environmental health : a global access science source 2020, 19(1):69.

20. Zhao Y, Wang S, Lang L, Huang C, Ma W, Lin H: Ambient fine and coarse particulate matter pollution and respiratory morbidity in Dongguan, China. Environmental pollution (Barking, Essex : 1987) 2017, 222:126-131.

21. Wang X, Zhang L, Yao Z, Ai S, Qian ZM, Wang H, BeLue R, Liu T, Xiao J, Li X et al: Ambient coarse particulate pollution and mortality in three Chinese cities: Association and attributable mortality burden. The Science of the total environment 2018, 628-629:1037-1042.

22. Cai M, Yazdi MAA, Mehdizadeh A, Hu Q, Vinel A, Davis K, Xian H, Megahed FM, Rigdon SE: The association between crashes and safety-critical events: Synthesized evidence from crash reports and naturalistic driving data among commercial truck drivers. Transportation Research Part C: Emerging Technologies 2021, 126:103016.

23. Revelle W, Condon DM, Wilt J, French JA, Brown A, Elleman LG: Web and phone based data collection using planned missing designs. Sage handbook of online research methods (2nd ed, p 578-595) Sage Publications, Inc 2016.

24. Chen R, Yang J, Chen D, Liu WJ, Zhang C, Wang H, Li B, Xiong P, Wang B, Wang Y et al: Air pollution and hospital outpatient visits for conjunctivitis: a time-series analysis in Tai'an, China. Environ Sci Pollut Res Int 2021, 28(12):15453-15461.

25. Lin H, Liu T, Xiao J, Zeng W, Li X, Guo L, Zhang Y, Xu Y, Tao J, Xian H et al: Mortality burden of ambient fine particulate air pollution in six Chinese cities: Results from the Pearl River Delta study. Environment international 2016, 96:91-97.

26. Nhung NTT, Schindler C, Dien TM, Probst-Hensch N, Perez L, Kunzli N: Acute effects of ambient air pollution on lower respiratory infections in Hanoi children: An eight-year time series study. Environ Int 2018, 110:139-148.

27. Zeka A, Zanobetti A, Schwartz J: Individual-level modifiers of the effects of particulate matter on daily mortality. Am J Epidemiol 2006, 163(9):849-859.

28. Davison AC, Hinkley DV: Bootstrap methods and their application: Cambridge university press; 1997.

29. Cai M, Liu E, Zhang R, Lin X, Rigdon SE, Qian Z, Belue R, Chang JJ: Comparing the Performance of Charlson and Elixhauser Comorbidity Indices to Predict In-Hospital Mortality Among a Chinese Population. Clin Epidemio/ 2020, 12:307-316.

30. R Core Team: R: A language and environment for statistical computing. 2013.

31. Zhang Q, Zheng Y, Tong D, Shao M, Wang S, Zhang Y, Xu X, Wang J, He H, Liu W et al: Drivers of improved PM2.5 air quality in China from 2013 to 2017. Proc Natl Acad Sci U S A 2019, 116(49):24463-24469. 
32. Lu X, Zhang S, Xing J, Wang Y, Chen W, Ding D, Wu Y, Wang S, Duan L, Hao J: Progress of air pollution control in China and its challenges and opportunities in the ecological civilization era. Engineering 2020.

33. Le T, Wang Y, Liu L, Yang J, Yung YL, Li G, Seinfeld JH: Unexpected air pollution with marked emission reductions during the COVID-19 outbreak in China. Science 2020, 369(6504):702-706.

34. Bowe B, Xie Y, Gibson AK, Cai M, van Donkelaar A, Martin RV, Burnett R, Al-Aly Z: Ambient Fine Particulate Matter Air Pollution and the Risk of Hospitalization among COVID-19 Positive Individuals: Cohort Study. Environment International 2021:106564.

35. Wang Y, Yuan Y, Wang Q, Liu C, Zhi Q, Cao J: Changes in air quality related to the control of coronavirus in China: Implications for traffic and industrial emissions. Sci Total Environ 2020, 731:139133.

\section{Figures}

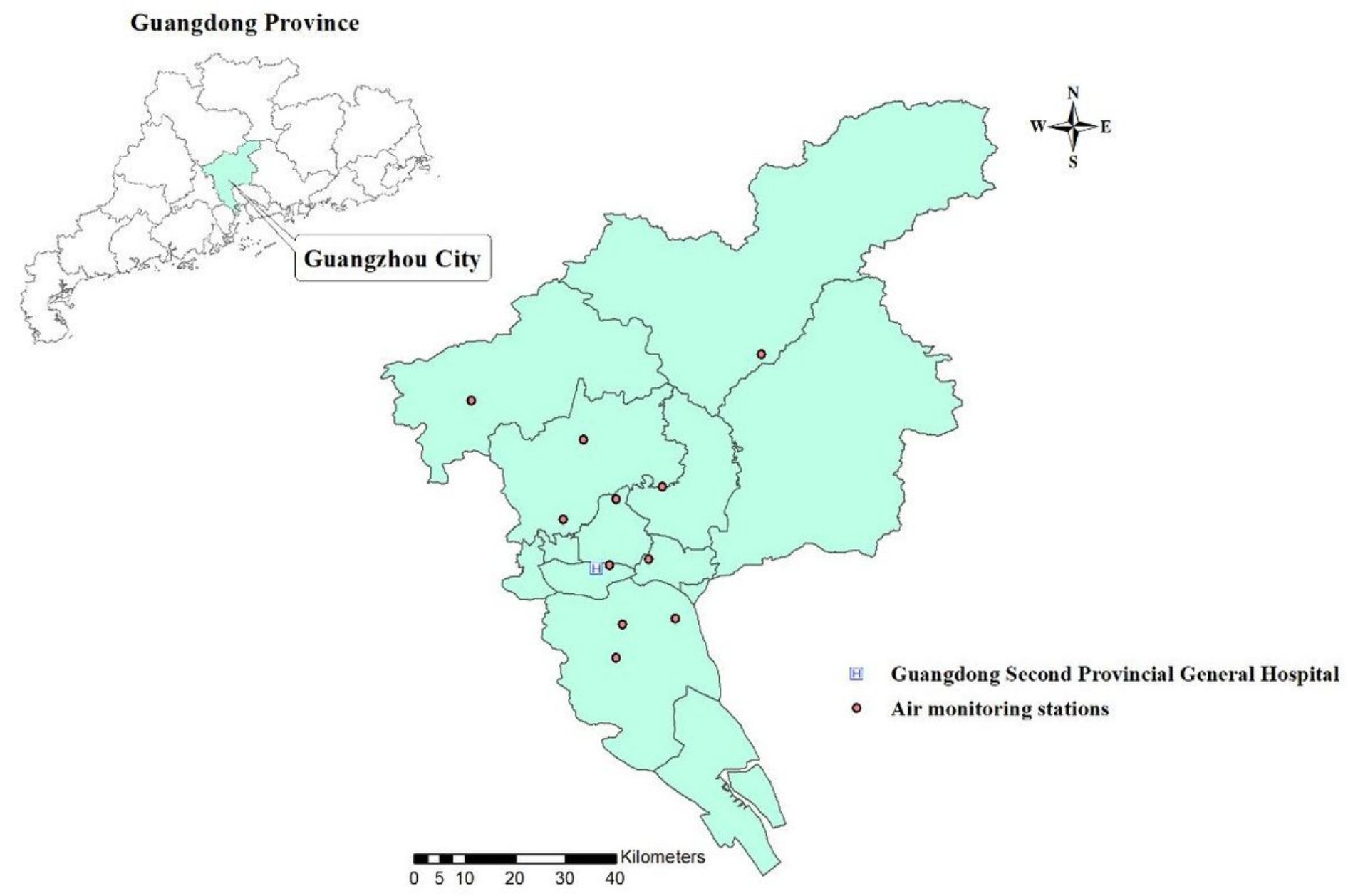

Figure 1

Geographical distribution of the sample hospitals and air monitoring stations. Note: The designations employed and the presentation of the material on this map do not imply the expression of any opinion 
whatsoever on the part of Research Square concerning the legal status of any country, territory, city or area or of its authorities, or concerning the delimitation of its frontiers or boundaries. This map has been provided by the authors.

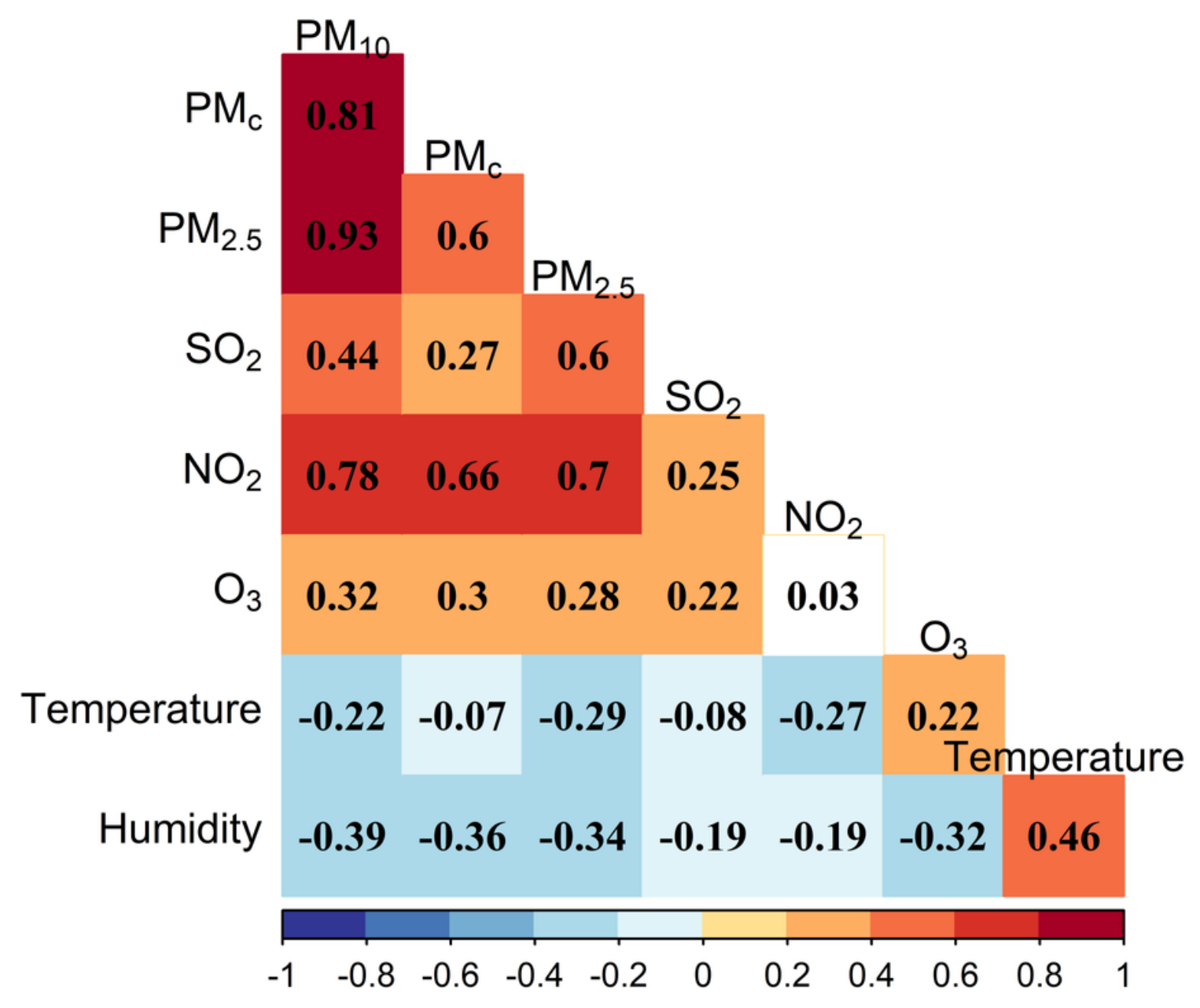

Figure 2

Correlation plot of the air pollutants and meteorological variables. The white cells indicate insignificance correlation coefficient (NO2 and 03). 

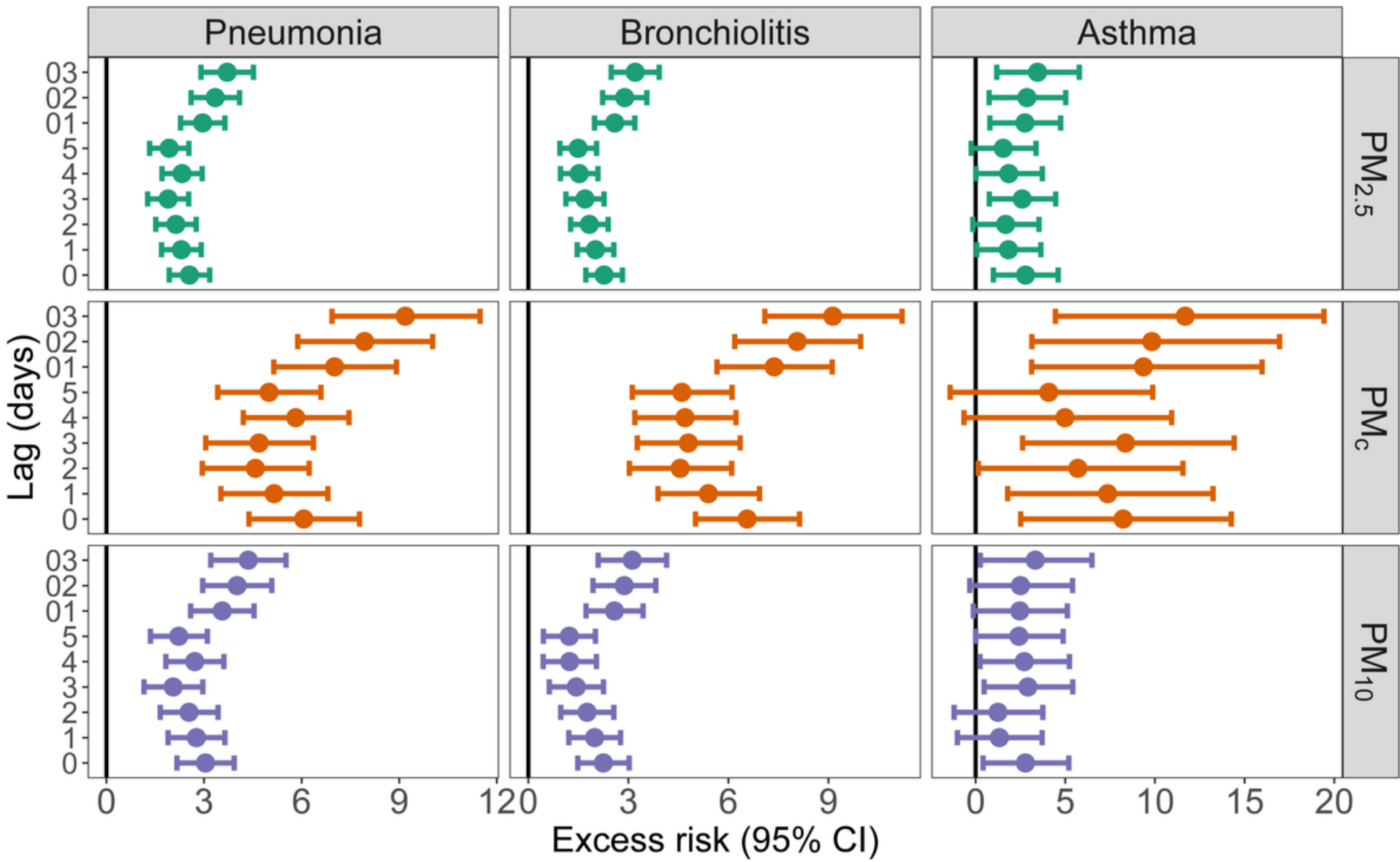

Figure 3

Excess risk (95\% confidence intervals) of hospital outpatient visits associated with $10 \mu \mathrm{g} / \mathrm{m} 3$ increase in PM10, PMc, and PM2.5.

\section{Supplementary Files}

This is a list of supplementary files associated with this preprint. Click to download.

- supplementalmaterials.docx 